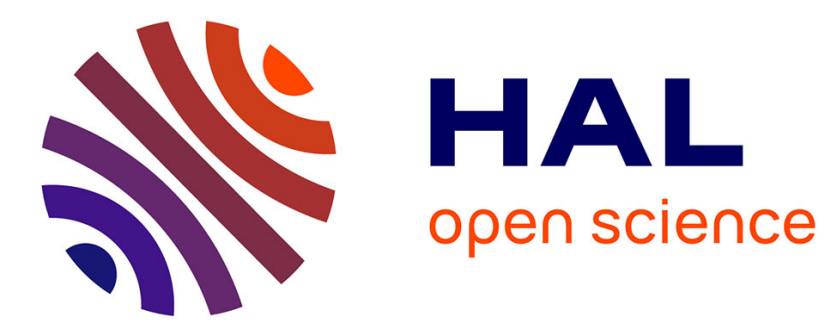

\title{
Design of smart oligo(ethylene glycol)-based biocompatible hybrid microgels loaded with magnetic nanoparticles
}

\author{
M. Boularas, E. Gombart, J.-F. Tranchant, Laurent Billon, M. Save
}

\section{- To cite this version:}

M. Boularas, E. Gombart, J.-F. Tranchant, Laurent Billon, M. Save. Design of smart oligo(ethylene glycol)-based biocompatible hybrid microgels loaded with magnetic nanoparticles. Macromolecular Rapid Communications, 2015, 36 (1), pp.79-83. 10.1002/marc.201400578 . hal-01563789

\section{HAL Id: hal-01563789 \\ https://hal-univ-pau.archives-ouvertes.fr/hal-01563789}

Submitted on 2 Dec 2020

HAL is a multi-disciplinary open access archive for the deposit and dissemination of scientific research documents, whether they are published or not. The documents may come from teaching and research institutions in France or abroad, or from public or private research centers.
L'archive ouverte pluridisciplinaire HAL, est destinée au dépôt et à la diffusion de documents scientifiques de niveau recherche, publiés ou non, émanant des établissements d'enseignement et de recherche français ou étrangers, des laboratoires publics ou privés. 
Article Type Communication

Design of Smart Oligo(ethylene glycol)-Based Biocompatible Hybrid Microgels loaded with Magnetic Nanoparticles

Mohamed Boularas, Emilie Gombart, Jean-François Tranchant, Laurent Billon* and Maud Save*

Dr. M. Boularas, Pr. L. Billon, Dr. M. Save

CNRS, Université de Pau \& Pays Adour, UMR 5254, IPREM, Equipe de Physique et Chimie des Polymères, 2 avenue du Président Angot, Pau, F-64053, France

Dr. E. Gombart, Dr. J. F. Tranchant

LVMH Recherche Parfums et Cosmétiques, 185 Av. de Verdun, St Jean de Braye, F-45804,

France

This paper reports a rational strategy for preparing smart oligo(ethylene glycol)-based hybrid microgels loaded with high content of homogeneously distributed pre-formed magnetic nanoparticles (up to $33 \mathrm{wt}-\%$ ). The strategy is based on the synthesis of the biocompatible multiresponsive microgels by precipitation copolymerization of di(ethylene glycol) methyl ether methacrylate, oligo(ethylene glycol) methyl ether methacrylate, methacrylic acid and oligo(ethylene glycol)diacrylate. An aqueous dispersion of pre-formed magnetic nanoparticles (NPs) is straightforwardly loaded into the microgels. We produced robust monodisperse thermoresponsive magnetic microgels exhibiting a constant value of the volume phase transition temperature whatever the NPs content. The homogeneous microstructure of the initial stimuli-responsive biocompatible microgels plays a crucial role for the design of unique well-defined ethylene glycol-based thermoresponsive hybrid microgels. 


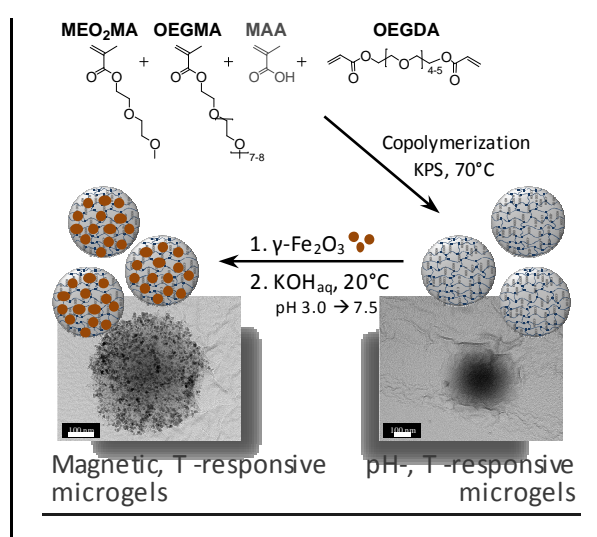

FIGURE FOR ToC_ABSTRACT 


\section{Introduction}

"Smart" stimuli-responsive microgels dispersed in aqueous media are fascinating crosslinked polymeric colloids which undergo a volume phase transition in response to different external stimuli. ${ }^{[1]}$ Thermoresponsive microgels are attractive materials for different emerging fields. ${ }^{[2]}$ Due to their propensity to uptake and release active species, they proved to be suitable candidates for biomedical applications. ${ }^{[3]}$ Their unique properties were also exploited in the field of materials to develop photonic crystals, ${ }^{[4]}$ stabilizers of pickering emulsions ${ }^{[5]}$ or responsive $\mathrm{CO}_{2}$-absorbents. ${ }^{[6]}$ Hybrid microgels composed of inorganic nanoparticles (NPs) widen the microgel properties by combining the shrinking properties of the polymer network with the intrinsic properties of the inorganic NPs (magnetic, optical or catalytic properties). Promising materials were prepared on the basis of thermoresponsive microgels loaded with iron oxide ${ }^{[7]}$ gold $^{[8]}$ silver $^{[9]}$ or quantum dot NPs. ${ }^{[7]}$ So far, the most studied hybrid microgels are based on poly(N-isopropylacrylamide) (PNiPAM $)^{[10]}$ and a few example on poly(N-vinylcaprolactam) (PVCL). ${ }^{[7 b, 9 a]}$ Nevertheless the potential toxicity of the acrylamidebased microgels might limit their application range. ${ }^{[11]}$ Recently, there has been a growing interest for copolymers based on oligo(ethylene glycol) methacrylates as suitable alternatives for the design of thermoresponsive polymers. ${ }^{[12]}$ These copolymers exhibit relevant features such as enhanced biocompatibility, tunable and sharp transition temperature. Whilst these thermoresponsive linear copolymers have been widely investigated for different purposes since $2006,{ }^{[12]}$ their microgel analogues have been scarcely investigated, ${ }^{[13]}$ and no attention was paid to the preparation of oligo(ethylene glycol) methacrylate-based hybrid microgels. The present work reports the synthesis and characterization of oligo(ethylene glycol) methacrylate-based magnetic thermoresponsive hybrid microgels. It should be mentioned that two different procedures have been proposed in the literature for the synthesis of hybrid microgels in aqueous dispersed media. The first one is based on the in-situ synthesis of NPs from the microsphere template while the second one consists in inserting the pre-formed 
nanoparticles into the interior of the microgel. Even though the first method has been widely investigated, ${ }^{[7 \mathrm{~b}, 7 \mathrm{~d}]}$ the second one has been less explored due to difficulties in achieving high concentration of NPs while limiting their aggregation and release. ${ }^{[14]}$ Nevertheless, this method deserves our attention as it represents a far more efficient way to preliminarily control the colloidal features of each separate particle and to ease material handling. Herein, we aim to address these issues by showing that multi-responsive methacrylic acid functionalized oligo(ethylene glycol) methacrylate-based microgels with fine tuned homogeneous microstructure can be relevant candidates to design stable monodisperse thermoresponsive hybrid microgels loaded with a high concentration of pre-formed magnetic NPs via a simple method.

\section{Results and Discussion}

The microgels are synthesized by surfactant-free precipitation polymerization in an environmentally friendly aqueous continuous phase (see details in Supporting Information). The overlay of the individual conversions of the monomers (di(ethylene glycol) methyl ether methacrylate $\left(\mathrm{MEO}_{2} \mathrm{MA}\right)$, oligo(ethylene glycol) methyl ether methacrylate (OEGMA) and methacrylic acid (MAA)) and the oligo(ethylene glycol) diacrylate (OEGDA) crosslinker indicates a homogeneous distribution of all units within the microgel (Figure S3, Supporting Information). It is interesting to note that the value of the apparent acid dissociation constant $\mathrm{p} K_{\mathrm{a}}$ of the $\mathrm{P}\left(\mathrm{MEO}_{2} \mathrm{MA}-\right.$ co-OEGMA-co-MAA) microgels exhibits a constant value as a function of the degree of ionization $\alpha$ of MAA (see Figure S6 in Supporting Information and equations (1) and (2)).

$$
\begin{aligned}
& \alpha=\frac{\left[M A^{-} N a^{+}\right]}{\left[M A^{-} N a^{+}\right]+[M A A]} \\
& p K_{a}=p H-\log \left(\frac{\alpha}{1-\alpha}\right)
\end{aligned}
$$


The plateau is consistent with the absence of the polyelectrolyte effect, ${ }^{[15]}$ hence supporting the homogeneous distribution of isolated carboxylic acid units from the outer to the inner of the $\mathrm{P}\left(\mathrm{MEO}_{2} \mathrm{MA}-c o\right.$-OEGMA-co-MAA) microgel.
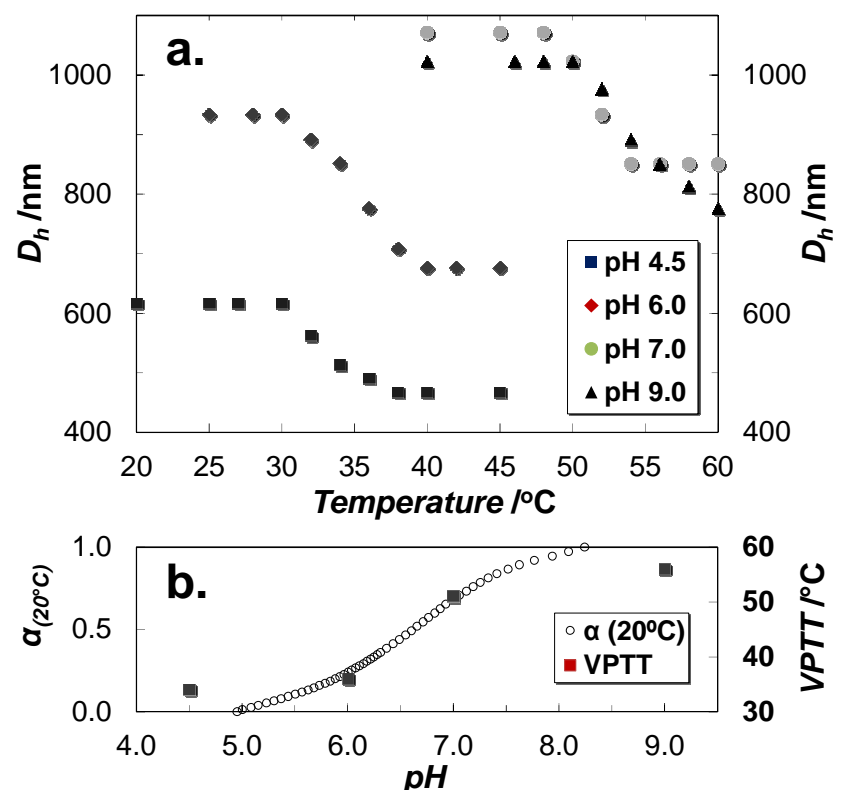

Figure 1. (a) Hydrodynamic diameter of $\mathrm{P}\left(\mathrm{MEO}_{2} \mathrm{MA}-\mathrm{co}\right.$-OEGMA-co-MAA) microgels $v s$ temperature measured at different $\mathrm{pH}$; (b) Evolution of VPTT and $\alpha$ s $\mathrm{pH}$.

The multiresponsiveness of the $\mathrm{P}\left(\mathrm{MEO}_{2} \mathrm{MA}-\right.$ co-OEGMA-co-MAA $)$ microgels was investigated by dynamic light scattering (DLS) at different temperatures and $\mathrm{pH}$ values. The $\mathrm{pH}$ value of the aqueous dispersion was adjusted between $\mathrm{pH} 4$ and $\mathrm{pH} 9$, thus scanning a degree of ionization of MAA from zero to one (Figure 1). The profile of the hydrodynamic diameter $\left(D_{\mathrm{h}}\right)$ versus temperature confirms the thermoresponsiveness of the $\mathrm{P}\left(\mathrm{MEO}_{2} \mathrm{MA}-\mathrm{co}\right.$ OEGMA-co-MAA) microgels with their ability to collapse with increasing temperature (Figure 1a). The biocompatible microgels proved to be concomitantly pH-responsive as the volume phase transition temperature (VPTT) increases from $34-36{ }^{\circ} \mathrm{C}$ at $\mathrm{pH} 4-5$ to $51-56$ ${ }^{\circ} \mathrm{C}$ at $\mathrm{pH}$ 7-9 (Figure 1b). Such increase of VPTT with $\mathrm{pH}$ is assigned to an increase of the degree of ionization of the methacrylic acid units which counterbalances the polymer collapse (Figure 1b). It is noteworthy that in contrast to $\mathrm{P}(\mathrm{NiPAM}-$ co-AA) or $\mathrm{P}(\mathrm{VCL}-$ co-MAA) microgels which displayed a broadening of thermal transition by increasing $\mathrm{pH}$ value ${ }^{[16]}$ the 
present $\mathrm{P}\left(\mathrm{MEO}_{2} \mathrm{MA}-c o-\mathrm{OEGMA}-c o-\mathrm{MAA}\right)$ thermoresponsive microgels possess a sharp collapse-to-swelling transition $\left(\Delta \mathrm{T}<10^{\circ} \mathrm{C}\right)$ for all $\mathrm{pH}$ values (Figure $1 \mathrm{~b}$ ).

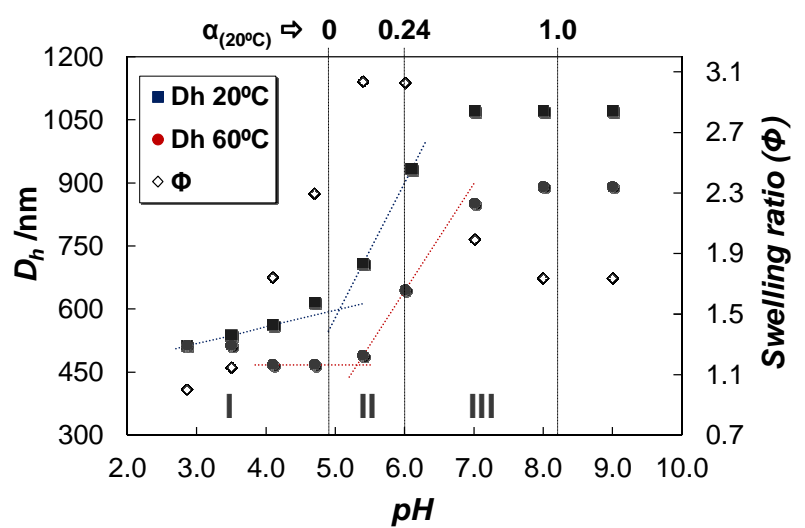

Figure 2. (a) Hydrodynamic diameter at $20^{\circ} \mathrm{C}$ (squares), $60^{\circ} \mathrm{C}$ (circles) and swelling ratio (diamonds) of $\mathrm{P}\left(\mathrm{MEO}_{2} \mathrm{MA}-\mathrm{co}-\mathrm{OEGMA}-\mathrm{co}-\mathrm{MAA}\right)$ microgels as a function of $\mathrm{pH}$.

The increase of the hydrodynamic diameter of the multiresponsive microgels from $0.5 \mu \mathrm{m}$ to ca $1.0 \mu \mathrm{m}$ is observed by raising $\mathrm{pH}$ from 4.9 to 8.0 (Figure 2, 9-fold increase of particle volume at $\left.20^{\circ} \mathrm{C}\right)$. Interestingly, this profile is observed at both temperatures $\left(20{ }^{\circ} \mathrm{C}\right.$ and 60 $\left.{ }^{\circ} \mathrm{C}\right)$, which shows that the increase of both electrostatic repulsions and internal osmotic pressure induced by sodium carboxylate units occurs in both swollen and collapsed states. ${ }^{[17]}$

The evolution of the microgel swelling ratio $(\Phi$, see equation (3)) with $\mathrm{pH}$ value shows three distinguished intervals (Figure 2).

$$
\phi=\left(\frac{D_{h, 60^{\circ} \mathrm{C}}}{D_{h, 20^{\circ} \mathrm{C}}}\right)^{3}
$$

In interval (I) corresponding to a degree of ionization of MAA equal to zero, lowering $\mathrm{pH}$ by adding $\mathrm{HCl}$ conveys an increase of salt concentration inducing a decrease of the swelling ability of the $\mathrm{P}\left(\mathrm{MEO}_{2} \mathrm{MA}-c o-O E G M A-c o-M A A\right)$ microgels due to salting-out effect ${ }^{[17 \mathrm{~b}]}(\Phi=$ 3 at $\mathrm{pH} 5.0, \Phi=1$ at $\mathrm{pH} 3.0$ ). The absence of shrinkage at $\mathrm{pH} 3.0$, together with the close values of the hydrodynamic diameter $\left(D_{\mathrm{h}}=510 \mathrm{~nm}\right.$, Figure 2) and the number-average diameter measured at dry state $\left(D_{\mathrm{TEM}}=460 \mathrm{~nm}\right.$, Figure $\left.\mathrm{S} 9 \mathrm{a}\right)$, are both features of a 
hydrophobic behavior of the microgels under acidic conditions. Interval (II) shows the maximum value of swelling ratio $(\Phi=3)$, indicating that $\mathrm{pH} 5.0-6.0$ is the optimum $\mathrm{pH}$ range to promote the highest volume transition of microgels. For a degree of ionization of MAA above $24 \%(\mathrm{pH}>6.0)$, the third interval corresponds to a decrease of the size change magnitude as the swelling ratio decreases from 3.0 to 1.7. This limited swelling is ascribed to the presence of repulsive electrostatic interactions between the homogeneously distributed sodium carboxylate units. In summary, the carboxylic acid-functionalized oligo(ethylene glycol)-based microgels represent novel promising multiresponsive biocompatible colloids. We highlighted their well-defined inner microstructure with a homogeneous distribution of both methacrylic acid and crosslinker. Noteworthy, this feature is an important point to enable the further design of stable magnetic hybrid thermoresponsive microgels.

The preparation of the hybrid microgels is based on a straightforward strategy. The first incorporation of the aqueous dispersion of pre-formed iron oxide NPs $\left(\gamma-\mathrm{Fe}_{2} \mathrm{O}_{3}\right)\left(D_{\mathrm{h}}=18\right.$ $\mathrm{nm})$ at $\mathrm{pH} 3.0$ is driven by polar interactions between the carboxylic acid units of microgels and the cationic charges of the NPs. The magnetic NPs are further destabilized inside the microgel by adjusting the $\mathrm{pH}$ at 7.0 corresponding to the point of zero charge of the maghemite NPs. ${ }^{[18]}$ It is important to emphasize that this strategy offers the unique opportunity to load high content of pre-formed magnetic NPs (up to $33 \mathrm{wt}-\%$ vs microgel) while maintaining the hybrid microgel stability in aqueous solution (see Figure 3 and 4). The loading of NPs is quantitative (see results of thermogravimetric analysis in Table S3, Supporting Information). Moreover, Figure 3 highlights the homogeneous distribution of the inorganic NPs into each microgel. Unlike the example of itaconic acid-functionalized PNiPAM microgels showing extensive desorption of magnetic NPs during the uptake step, ${ }^{[14]}$ the present $\gamma-\mathrm{Fe}_{2} \mathrm{O}_{3}$-loaded biocompatible microgels do not exhibit any NP release (Figure 3). 


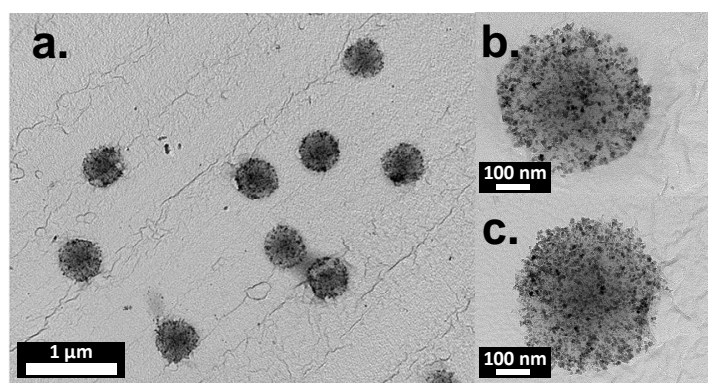

Figure 3. Transmission Electron micrographs of $\gamma$ - $\mathrm{Fe}_{2} \mathrm{O}_{3}-\mathrm{P}\left(\mathrm{MEO}_{2} \mathrm{MA}-\mathrm{co}-\mathrm{PEGMA-co}-\mathrm{MAA}\right)$ hybrid microgels loaded with 16 wt-\% (a and b) or 33 wt-\% (c) of magnetic NPs.

For the present system, it is noteworthy that the methacrylic acid units play a crucial role to promote interaction with magnetic NPs and to ensure the stability of hybrid microgels. Indeed, when using MAA-free $\mathrm{P}\left(\mathrm{MEO}_{2} \mathrm{MA}-\mathrm{co}\right.$-OEGMA) microgels, NPs were expelled outside (see Figure S10, Supporting Information) along with microgel flocculation. On the other hand, the hybrid $\gamma-\mathrm{Fe}_{2} \mathrm{O}_{3}-\mathrm{P}\left(\mathrm{MEO}_{2} \mathrm{MA}-\mathrm{co}\right.$-OEGMA-co-MAA) microgels loaded with maghemite were highly stable and monodisperse (Figure 3 and 4c).

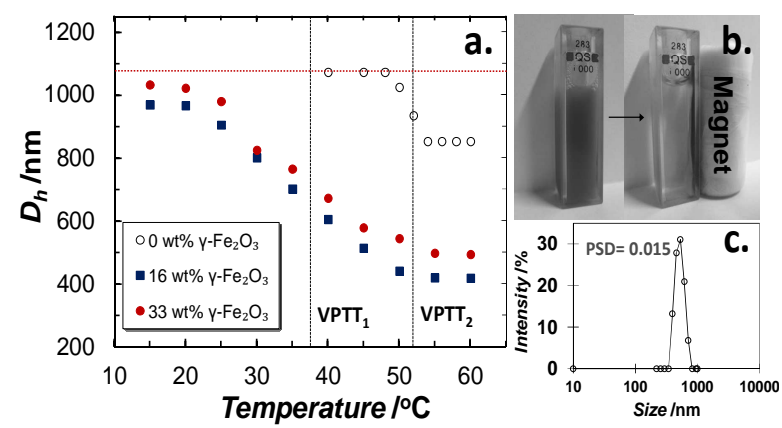

Figure 4. Features of $\gamma-\mathrm{Fe}_{2} \mathrm{O}_{3}-\mathrm{P}\left(\mathrm{MEO}_{2} \mathrm{MA}-\mathrm{co}\right.$-OEGMA-co-MAA) hybrid microgels: (a) $D_{\mathrm{h}}$ (at $\mathrm{pH}$ 7) $v s$ temperature for various contents of $\gamma-\mathrm{Fe}_{2} \mathrm{O}_{3}$; (b) dispersion of hybrid microgels under permanent magnet ; (c) particle size distribution at $55^{\circ} \mathrm{C}$ (PSD).

An important observation from Figure $4 \mathrm{a}$ is that the magnetic hybrid microgels still exhibit a swelling-deswelling behavior with a reduction of the $D_{\mathrm{h}}$ value from $1.0 \mu \mathrm{m}$ at $20{ }^{\circ} \mathrm{C}$ to $0.4-0.5$ $\mu \mathrm{m}$ at $60{ }^{\circ} \mathrm{C}$. Starting from a similar hydrodynamic diameter at swollen state $\left(D_{\mathrm{h}, 20^{\circ} \mathrm{C}} \sim 1.05\right.$ $\mu \mathrm{m})$, the ability of the magnetic $\gamma$ - $\mathrm{Fe}_{2} \mathrm{O}_{3}-\mathrm{P}\left(\mathrm{MEO}_{2} \mathrm{MA}-c o\right.$-OEGMA-co-MAA) microgels to collapse is significantly higher than the one of the initial $\mathrm{P}\left(\mathrm{MEO}_{2} \mathrm{MA}-\right.$ co-OEGMA-co-MAA $)$ microgels $\left(\Phi_{\text {hybrid microgel }}=25>\Phi_{\text {microgel }}=2\right)$. This water expulsion can be an important point 
for future release of active species. Furthermore, the presence of magnetic nanoparticles induces a noticeable decrease of the microgel VPTT from $52{ }^{\circ} \mathrm{C}$ to $37{ }^{\circ} \mathrm{C}$, a suitable temperature range for the fields of cosmetics and health care. This transition temperature is moreover constant whatever the NP content (Figure 4). Both of these considerations illustrate the homogeneous distribution of NPs as the volume phase transition behavior of the $\gamma-\mathrm{Fe}_{2} \mathrm{O}_{3^{-}}$ $\mathrm{P}\left(\mathrm{MEO}_{2} \mathrm{MA}-\mathrm{co}\right.$-OEGMA-co-MAA) hybrid microgels is different from PNIPAM- or PVCLbased composite microgels exhibiting a heterogeneous distribution of magnetic nanoparticles. ${ }^{[7 \mathrm{~b}, 7 \mathrm{c}]}$ Interestingly, the well-separated magnetic nanoparticles, interacting with the homogeneously distributed carboxylic acid functions in the present oligo(ethylene oxide)based network, does not hinder the change of copolymer conformation. The polar interactions more likely limits the ionization of the acid functions at $\mathrm{pH} 7$, hence lowering both the VPTT value and the hydrodynamic diameter of the collapse hybrid microgels in comparison with the precursor microgels (Figure $4 \mathrm{a}, \Delta_{\mathrm{VPTT}}=15^{\circ} \mathrm{C}, \Delta_{\mathrm{Dh}, 60}{ }^{\circ} \mathrm{C}=400 \mathrm{~nm}$ ).

\section{Conclusions}

In conclusion, we designed for the first time smart oligo(ethylene glycol)-based biocompatible hybrid thermoresponsive microgels containing a high fraction of magnetic NPs. The significance of the present work is to use a simple method for the preparation of such microgels by loading a high content of pre-formed magnetic nanoparticles, up to 33 wt$\%$ of $\gamma-\mathrm{Fe}_{2} \mathrm{O}_{3}$ versus microgels, into the biocompatible microgels while maintaining simultaneously perfect colloidal stability, monodisperse particles, sharp thermoresponsiveness, intense collapse-to-swelling transition and quantitative nanoparticle encapsulation. The homogeneous distribution in MAA of the multiresponsive oligo(ethylene glycol)-based microgels proved to be the key parameter to overcome the difficulties which usually arise from this method. Interestingly, a robust system is proposed here as the volume 
phase transition temperature of the hybrid thermoresponsive microgels is not influenced by the fraction of magnetic nanoparticles. As the collapse-to-swelling ability of the microgel is maintained, the present system could offer the opportunity to tune the VPTT of the hybrid microgels by selecting the initial molar ratio of OEGMA and $\mathrm{MEO}_{2} \mathrm{MA}$. In summary, we successfully prepared stable monodisperse oligo(ethylene glycol)-based hybrid colloids combining multiple properties: biocompatibility, thermo-dependent swelling ability with tunable transition temperature and magnetic properties. The proposed strategy via the rational design of smart multi-functional polymeric vehicles by simple association of two distinct preformed aqueous colloidal dispersions with controlled features, offers interesting perspectives for different fields of applications such as cosmetics or health care.

\section{Experimental section}

The details concerning microgel synthesis, monitoring of individual monomer conversion, potentiometric and conductometric titration, evolution of $\mathrm{pKa}$ as a function of the ionization degree, TGA analysis, TEM images of magnetic nanoparticles and hydrid microgels are gathered in Supporting Information.

\section{Supporting Information}

Supporting Information is available from the Wiley Online Library or from the author

Acknowledgements: The authors are grateful to $\mathrm{LVMH}$ for funding $\mathrm{MB} \mathrm{PhD}, \mathrm{CNRS}$ and UPPA for MS and LB. The authors would like to acknowledge T. Pouget (LVMH) for TEM, A. Khoukh (IPREM EPCP) for NMR, J. Rieger and L. Bouteiller (UMR8232) for supplying Nanosizer90 for DLS of hybrid microgels. 
Keywords: Polymerization, Microgels, Stimuli-responsive, Hybrid Materials, Magnetic Nanoparticles

[1] (a) I. Berndt, J. S. Pedersen, W. Richtering, J. Am. Chem. Soc. 2005, 127, 9372; (b) C. M. Burba, S. M. Carter, K. J. Meyer, C. V. Rice, J. Phys. Chem. B 2008, 112, 10399; (c) Y. Hertle, T. Hellweg, J. Mater. Chem. B 2013, 1, 5874; (d) V. Lapeyre, I. Gosse, S. Chevreux, V. Ravaine, Biomacromolecules 2006, 7, 3356.

[2] S. Nayak, L. A. Lyon, Angew. Chem. Int. Ed. 2005, 44, 7686.

[3] (a) Z. Dai, T. Ngai, J. Polym. Sci. A Polym. Chem. 2013, 51, 2995; (b) M. J. Serpe, K. A. Yarmey, C. M. Nolan, L. A. Lyon, Biomacromolecules 2005, 6, 408; (c) N. M. B. Smeets, T. Hoare, J. Polym. Sci. A Polym. Chem. 2013, 51, 3027.

[4] (a) Q. M. Zhang, W. Xu, M. J. Serpe, Angew. Chem. Int. Ed. 2014, 53, 4827; (b) C. D. Jones, L. A. Lyon, J. Am. Chem. Soc. 2003, 125, 460; (c) S. B. Debord, L. A. Lyon, J. Phys. Chem. B 2003, 107, 2927.

[5] (a) K. Geisel, L. Isa, W. Richtering, Angew. Chem. Int. Ed. 2014, 53, 4905; (b) M. Destribats, M. Eyharts, V. Lapeyre, E. Sellier, I. Varga, V. Ravaine, V. Schmitt, Langmuir 2014, 30, 1768; (c) S. Wiese, A. C. Spiess, W. Richtering, Angew. Chem. Int. Ed. 2013, 52, 576.

[6] M. Yue, Y. Hoshino, Y. Ohshiro, K. Imamura, Y. Miura, Angew. Chem. Int. Ed. 2014, $53,2654$.

[7] (a) W. Feng, W. Lv, J. Qi, G. Zhang, F. Zhang, X. Fan, Macromol. Rapid Commun. 2012, 33, 133; (b) A. Pich, S. Bhattacharya, Y. Lu, V. Boyko, H.-J. P. Adler, Langmuir 2004, 20, 10706; (c) J. Rubio-Retama, N. E. Zafeiropoulos, C. Serafinelli, R. Rojas-Reyna, B. Voit, E. Lopez Cabarcos, M. Stamm, Langmuir 2007, 23, 10280; (d) J. Zhang, S. Xu, E. Kumacheva, J. Am. Chem. Soc. 2004, 126, 7908. 
(a) C. Echeverria, C. Mijangos, Macromol. Rapid Commun. 2010, 31, 54; (b) I.

Gorelikov, L. M. Field, E. Kumacheva, J. Am. Chem. Soc. 2004, 126, 15938.

[9] (a) A. Pich, A. Karak, Y. Lu, A. K. Ghosh, H.-J. P. Adler, Macromol. Rapid Commun.

2006, 27, 344; (b) Y. Dong, Y. Ma, T. Zhai, F. Shen, Y. Zeng, H. Fu, J. Yao, Macromol. Rapid Commun. 2007, 28, 2339.

[10] (a) J. K. Oh, J. M. Park, Progress in Polymer Science 2011, 36, 168; (b) M. Karg, T. Hellweg, J. Mater. Chem. 2009, 19, 8714.

[11] H. Vihola, A. Laukkanen, L. Valtola, H. Tenhu, J. Hirvonen, Biomaterials 2005, 26, 3055 .

[12] (a) J. F. Lutz, Adv. Mater. 2011, 23, 2237; (b) J.-F. Lutz, Ö. Akdemir, A. Hoth, J. Am. Chem. Soc. 2006, 128, 13046.

[13] T. Cai, M. Marquez, Z. Hu, Langmuir 2007, 23, 8663.

[14] F. Sauzedde, A. Elaïssari, C. Pichot, Colloid. Polym. Sci. 1999, 277, 1041.

[15] T. Hoare, R. Pelton, Langmuir 2006, 22, 7342.

[16] (a) Y. Wang, J. Nie, B. Chang, Y. Sun, W. Yang, Biomacromolecules 2013, 14, 3034;

(b) T. Hoare, R. Pelton, Macromolecules 2004, 37, 2544.

[17] (a) A. A. Polotsky, F. A. Plamper, O. V. Borisov, Macromolecules 2013, 46, 8702; (b) K. Kratz, T. Hellweg, W. Eimer, Colloids and Surfaces A: Physicochem. Eng. Aspects 2000, $170,137$.

[18] (a) I. T. Lucas, S. Durand-Vidal, E. Dubois, J. Chevalet, P. Turq, J. Phys. Chem. C 2007, 111, 18568; (b) G. R. Patzke, Y. Zhou, R. Kontic, F. Conrad, Angew. Chem. Int. Ed. 2011, 50, 826 . 


\section{Table of Content}

Smart biocompatible oligo(ethylene glycol)-based hybrid microgels loaded with a high content of homogeneously distributed pre-formed magnetic nanoparticles are synthesized by a simple two step method. The monodisperse thermoresponsive magnetic microgels exhibit a constant value of the volume phase transition temperature up to high NPs content (33 wt-\%) thanks to the homogeneous microstructure of the initial biocompatible microgels

Mohamed Boularas, Emilie Gombart, Jean-François Tranchant, Laurent Billon* and Maud Save*

Design of Smart Oligo(ethylene glycol)-Based Biocompatible Hybrid Microgels loaded with Magnetic Nanoparticles

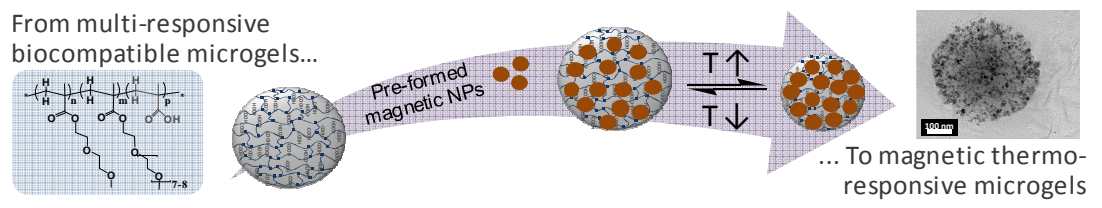




\section{Supporting Information}

for Macromol. Rapid Commun.,

Design of Smart Oligo(ethylene glycol)-Based Biocompatible Hybrid Microgels loaded with Magnetic Nanoparticles

Mohamed Boularas, Emilie Gombart, Jean-François Tranchant, Laurent Billon* and Maud Save*

\section{Materials}

Iron (II) chloride tetrahydrate $\left(\mathrm{FeCl}_{2} \cdot 4 \mathrm{H}_{2} \mathrm{O}\right.$, Aldrich), iron (III) chloride hexahydrate $\left(\mathrm{FeCl}_{3} \cdot 6 \mathrm{H}_{2} \mathrm{O}, 6 \mathrm{H}_{2} \mathrm{O}\right.$, Aldrich), ferric nitrate $\left(\mathrm{Fe}\left(\mathrm{NO}_{3}\right)_{3}\right.$, Aldrich), ammonium hydroxide $\left(\mathrm{NH}_{4} \mathrm{OH}, 28-30 \% \mathrm{w} / \mathrm{w}\right.$, Aldrich), nitric acid $\left(\mathrm{HNO}_{3}\right.$, Aldrich) and hydrochloric acid $(\mathrm{HCl}$, $36 \% \mathrm{w} / \mathrm{w}, \mathrm{ABCR})$ were used for the synthesis of maghemite nanoparticles without further purification. Di(ethylene glycol) methyl ether methacrylate $\left(\mathrm{MEO}_{2} \mathrm{MA} 95 \%\right.$, Aldrich), oligo(ethylene glycol) methyl ether methacrylate (OEGMA, monomethyl terminated with 8 EG repeat units, number average weight $\mathrm{M}_{\mathrm{n}}=475 \mathrm{~g} \cdot \mathrm{mol}^{-1}$, Aldrich), oligo(ethylene glycol)diacrylate (OEGDA, number average weight $\mathrm{M}_{\mathrm{n}}=250 \mathrm{~g} \cdot \mathrm{mol}^{-1}$, Aldrich) and potassium persulfate (KPS, 99\%, ABCR) were used as received for the synthesis of $\mathrm{P}\left(\mathrm{MEO}_{2} \mathrm{MA}-\mathrm{co}\right.$ OEGMA-co-MAA) microgels. The water used for the microgel synthesis and characterization was purified using a Millipore Milli-Q system.

\section{Synthesis of P(MEO $2 \mathrm{MA-co-OEGMA-co-MAA)} \mathrm{microgels} \mathrm{(Table} \mathrm{S1)}$}

The microgels are synthesized by surfactant-free precipitation polymerization in an aqueous continuous phase. Starting from a monophasic solution, the microgels are prepared by precipitation copolymerization of di(ethylene glycol) methyl ether methacrylate $\left(\mathrm{MEO}_{2} \mathrm{MA}\right)$, oligo(ethylene glycol) methyl ether methacrylate (OEGMA) and methacrylic acid (MAA) in the presence of oligo(ethylene glycol)diacrylate (OEGDA) as crosslinker and potassium persulfate (KPS) as initiator. At the initial stage, all reactants are soluble in water and the polymer chains precipitate during polymerization carried out at $70^{\circ} \mathrm{C}$ to form crosslinked colloidal particles stabilized by the sulfate charges ( $2.1 \mathrm{wt}-\%$ of solids content). The initial feed composition is $\left[\mathrm{MEO}_{2} \mathrm{MA}\right.$ :OEGMA:MAA:OEGDA] $=[84: 9: 5: 2]$ mol-\%. Crosslinker OEGDA and initiator KPS were kept at $1.92 \mathrm{~mol} \%$ and $0.86 \mathrm{~mol} \%$ versus the total vinylic molecules $\left(\mathrm{MEO}_{2} \mathrm{MA}+\mathrm{OEGMA}+\right.$ OEGDA). Briefly, $\mathrm{MEO}_{2} \mathrm{MA}$ (0.966 g, $\left.5.14 \mathrm{mmol}\right)$, 
OEGMA (0.272 g, $0.573 \mathrm{mmol})$ and OEGDA (0.029 g, $0.117 \mathrm{mmol})$ were dissolved in 57.5 $\mathrm{mL}$ of water. The reaction mixture was first introduced in a $250 \mathrm{~mL} 3$-neck round- bottom flask equipped with a mechanical stirrer set at $150 \mathrm{rpm}$ ) and purged with nitrogen for 45 minutes at room temperature to remove oxygen. A solution of MAA $(0.026 \mathrm{~g}, 0.305 \mathrm{mmol}$ dissolved in $2 \mathrm{~mL}$ of water) was then introduced into the round bottom flask. The mixture was heated up to $70{ }^{\circ} \mathrm{C}$ prior to introduce the KPS solution $(14.3 \mathrm{mg}$ dissolved in $2.5 \mathrm{~mL}$ of degassed water) into the reactor in order to initiate the polymerization. The reaction mixture became turbid in few minutes and was kept at $70{ }^{\circ} \mathrm{C}$ for 6 hours $(150 \mathrm{rpm})$ to complete the reaction. The individual conversions of MAA, OEGDA and ethylene glycol-based methacrylates were monitored by analyzing the polymerization medium by off-line ${ }^{1} \mathrm{H}$ NMR in $\mathrm{D}_{2} \mathrm{O} / \mathrm{H}_{2} \mathrm{O}(1: 9 \mathrm{v} / \mathrm{v})$.

The microgels were then purified by 5 centrifugation/redispersion cycles $(10000 \mathrm{rpm}, 30$ min) with milliQ grade water and finally stored at room temperature.Table S1

Table S1: Synthesis of P(MEO $2 \mathrm{MA-co-OEGMA-co-MAA)} \mathrm{microgels}$

\begin{tabular}{|c|c|c|c|c|}
\hline $\begin{array}{c}{\left[\mathrm{MEO}_{2} \mathrm{MA}\right]_{0}{ }^{\mathrm{a}}} \\
\mathrm{mmol}^{-L^{-1}}\end{array}$ & $\begin{array}{c}\text { [OEGMA } 475]_{0}{ }^{\mathrm{a}} \\
\text { mmol.L }^{-1}\end{array}$ & $\begin{array}{l}{[\mathrm{MAA}]_{0}{ }^{\mathrm{a}}} \\
\text { mmol. }^{-1}\end{array}$ & $\begin{array}{c}\text { [OEGDA } 250]_{0}{ }^{\mathrm{a}} \\
\text { mmol. } L^{-1}\end{array}$ & $\begin{array}{l}{[\mathrm{KPS}]_{0}{ }^{\mathrm{a}}} \\
\text { mmol. } L^{-1}\end{array}$ \\
\hline 83.9 & 9.36 & 4.99 & 1.92 & 0.86 \\
\hline
\end{tabular}

${ }^{\text {a }}$ Molar initial feed ratio: [MEO $\left.{ }_{2} \mathrm{MA}: O E G M A: M A A: O E G D A\right] ~=~[84: 9: 5: 2]$ mol-\%., solid content at $100 \%$ of monomer conversion $=2.1 \mathrm{wt}-\% ; \mathrm{T}=70^{\circ} \mathrm{C}$.

\section{Monomer Conversion Measurement}

In order to monitor the individual monomer conversion $(x)$, the surfactant free precipitation polymerization was performed as described above but adding trioxane as internal standard $\left(\mathrm{n}_{\text {trioxane }}=0.1\left(\mathrm{n}_{\mathrm{OEGMA}}+\mathrm{n}_{\mathrm{MEO}_{2} \mathrm{MA}}+\mathrm{n}_{\mathrm{OEGDA}}+\mathrm{n}_{\mathrm{MAA}}\right)\right.$. For that purpose, samples were withdrawn at different time intervals and deuterated water $(10 \mathrm{v}-\%)$ was added in each sample for proton NMR analysis (Figure S1 and Figure S2). The conversions of $\left(\mathrm{MEO}_{2} \mathrm{MA}+\right.$, OEGMA), MAA and OEGDA were calculated from the ratio of their respective peak integration with the integration of trioxane, according to equation Eq. $\mathbf{S 1}$ and monomer conversion versus time is represented in Figure S3.

$$
x=1-\frac{[M]_{t}}{[M]_{0}}=1-\frac{[M]_{t} /[\text { Trioxane }]_{t}}{[M]_{0} /[\text { Trioxane }]_{0}}=1-\frac{I_{M(t)} / I_{\text {Trioxane }(t)}}{I_{M(0)} / I_{\text {Trioxane }(0)}}
$$

With $I_{M}$ and $I_{\text {Trioxane }}$ are the values of the peak integration of monomer $M$ and internal standard (trioxane) at initial time $\mathrm{t}_{0}$ and sampling time $\mathrm{t}$. 
${ }^{1} \mathrm{H}$ NMR $\left(\mathrm{H}_{2} \mathrm{O}: \mathrm{D}_{2} \mathrm{O}\right.$ 90:10, $\left.400 \mathrm{MHz}\right)$ : $\mathbf{M E O}_{2} \mathbf{M A}: \delta(\mathrm{ppm}): 1.85$ (s, 3H, $\left.\left(\mathrm{C}=\mathrm{C}-\mathbf{C H}_{3}\right)\right), 3.3$ (s, $\left.3 \mathrm{H}, \mathrm{O}-\mathbf{C H}_{3}\right), 3.54$ (d, $\left.2 \mathrm{H}, \mathrm{O}-\mathrm{CH}_{2}-\mathbf{C H}_{2}-\mathrm{O}-\mathrm{CH}_{3}\right), 3.64\left(\mathrm{~d}, 2 \mathrm{H}, \mathrm{O}-\mathbf{C H}_{2}-\mathrm{CH}_{2}-\mathrm{O}-\mathrm{CH}_{3}\right), 3.74$ (d, $\left.2 \mathrm{H}, \mathrm{C}=\mathrm{C}-(\mathrm{OC})-\mathrm{O}-\mathrm{CH}_{2}-\mathbf{C H}_{2}-\mathrm{O}-\right), 4.26\left(\mathrm{~d}, 2 \mathrm{H}, \mathrm{C}=\mathrm{C}-(\mathrm{OC})-\mathrm{O}-\mathbf{C H}_{2}-\mathrm{CH}_{2}-\mathrm{O}-\right), 5.65$ (dd, $1 \mathrm{H}$, $\left.\left(\mathbf{H}_{\text {trans }}-\mathrm{HC}=\mathrm{C}\left(\mathrm{CH}_{3}\right)-\mathrm{C}(=\mathrm{O}) \mathrm{O}-\right)\right), 6.1\left(\mathrm{dd}, 1 \mathrm{H},\left(\mathrm{H}_{\text {cis }}-\mathrm{HC}=\mathrm{CH}\left(\mathrm{CH}_{3}\right)-\mathrm{C}(=\mathrm{O}) \mathrm{O}-\right)\right)$. OEGMA : $\delta$ (ppm): 1.85 (s, 3H, (C=C-CH $\left.\mathbf{C H}_{3}\right), 3.3$ (s, 3H, O-CH $\left.\mathbf{C H}_{3}\right), 3.54$ (d, $\left.2 \mathrm{H}, \mathrm{O}-\mathrm{CH}_{2}-\mathbf{C H}_{2}-\mathrm{O}-\mathrm{CH}_{3}\right), 3.64$ (d, 26-30H, O- $\left.\mathbf{C H}_{2}-\mathrm{CH}_{2}-\mathrm{O}-\mathrm{CH}_{3}\right), 3.74$ (d, $\left.2 \mathrm{H}, \mathrm{C}=\mathrm{C}-(\mathrm{OC})-\mathrm{O}-\mathrm{CH}_{2}-\mathbf{C H}_{2}-\mathrm{O}-\right), 4.26$ (d, $2 \mathrm{H}$, $\left.\mathrm{C}=\mathrm{C}-(\mathrm{OC})-\mathrm{O}-\mathrm{CH}_{2}-\mathrm{CH}_{2}-\mathrm{O}-\right), 5.92\left(\mathrm{dd}, 1 \mathrm{H},\left(\mathbf{H}_{\text {trans }}-\mathrm{HC}=\mathrm{C}\left(\mathrm{CH}_{3}\right)-\mathrm{C}(=\mathrm{O}) \mathrm{O}-\right)\right), 6.1\left(\mathrm{dd}, 1 \mathrm{H},\left(\mathbf{H}_{\text {cis }^{-}}\right.\right.$ $\left.\left.\mathrm{HC}=\mathrm{C}\left(\mathrm{CH}_{3}\right)-\mathrm{C}(=\mathrm{O}) \mathrm{O}-\right)\right)$, MAA: $\delta(\mathrm{ppm}): 1.81\left(\mathrm{~s}, 3 \mathrm{H}, \mathrm{C}=\mathrm{C}-\left(\mathbf{C H}_{3}\right)\right) .5 .55\left(\mathrm{dd}, 1 \mathrm{H}, \mathbf{H}_{\text {trans }^{-}}\right.$ $\left.\left.\left.\left.\mathrm{HC}=\mathrm{C}\left(\mathrm{CH}_{3}\right)-\mathrm{C}(=\mathrm{O}) \mathrm{OH}\right)\right) .5 .93 \mathrm{dd}, 1 \mathrm{H}, \mathbf{H}_{\text {cis }}-\mathrm{HC}=\mathrm{C}\left(\mathrm{CH}_{3}\right)-\mathrm{C}(=\mathrm{O}) \mathrm{OH}\right)\right)$, OEGDA : $\delta(\mathrm{ppm})$ : $3.64\left(\mathrm{~d}, 16-12 \mathrm{H}, \mathrm{O}-\mathbf{C H}_{2}-\mathrm{CH}_{2}-\mathrm{O}-\right), 3.74$ (d, 4H, C=C-(OC)-O- $\left.\mathrm{CH}_{2}-\mathbf{C H}_{2}-\mathrm{O}-\right), 4.26$ (d, $4 \mathrm{H}$, $\left.\mathrm{C}=\mathrm{C}-(\mathrm{OC})-\mathrm{O}-\mathrm{CH}_{2}-\mathrm{CH}_{2}-\mathrm{O}-\right), \quad 5.92 \quad\left(\mathrm{dd}, \quad 1 \mathrm{H}, \quad\left(\mathbf{H}_{\text {trans }}-\mathrm{HC}=\mathrm{CH}-\mathrm{C}(=\mathrm{O}) \mathrm{O}-\right)\right), \quad 6.1 \quad(\mathrm{dd}, \quad 1 \mathrm{H}$, $\left.\left(\mathrm{H}_{2} \mathrm{C}=\mathrm{CH}-\mathrm{C}(=\mathrm{O}) \mathrm{O}-\right)\right), 6.36\left(\mathrm{dd}, 1 \mathrm{H},\left(\mathbf{H}_{\mathrm{cis}}-\mathrm{HC}=\mathrm{CH}-\mathrm{C}(=\mathrm{O}) \mathrm{O}-\right)\right)$, trioxane: $\delta(\mathrm{ppm})=5.1(\mathrm{~s}, 3 \mathrm{H}$, $\left.\left(\mathrm{CH}_{2}\right)\right)$. 


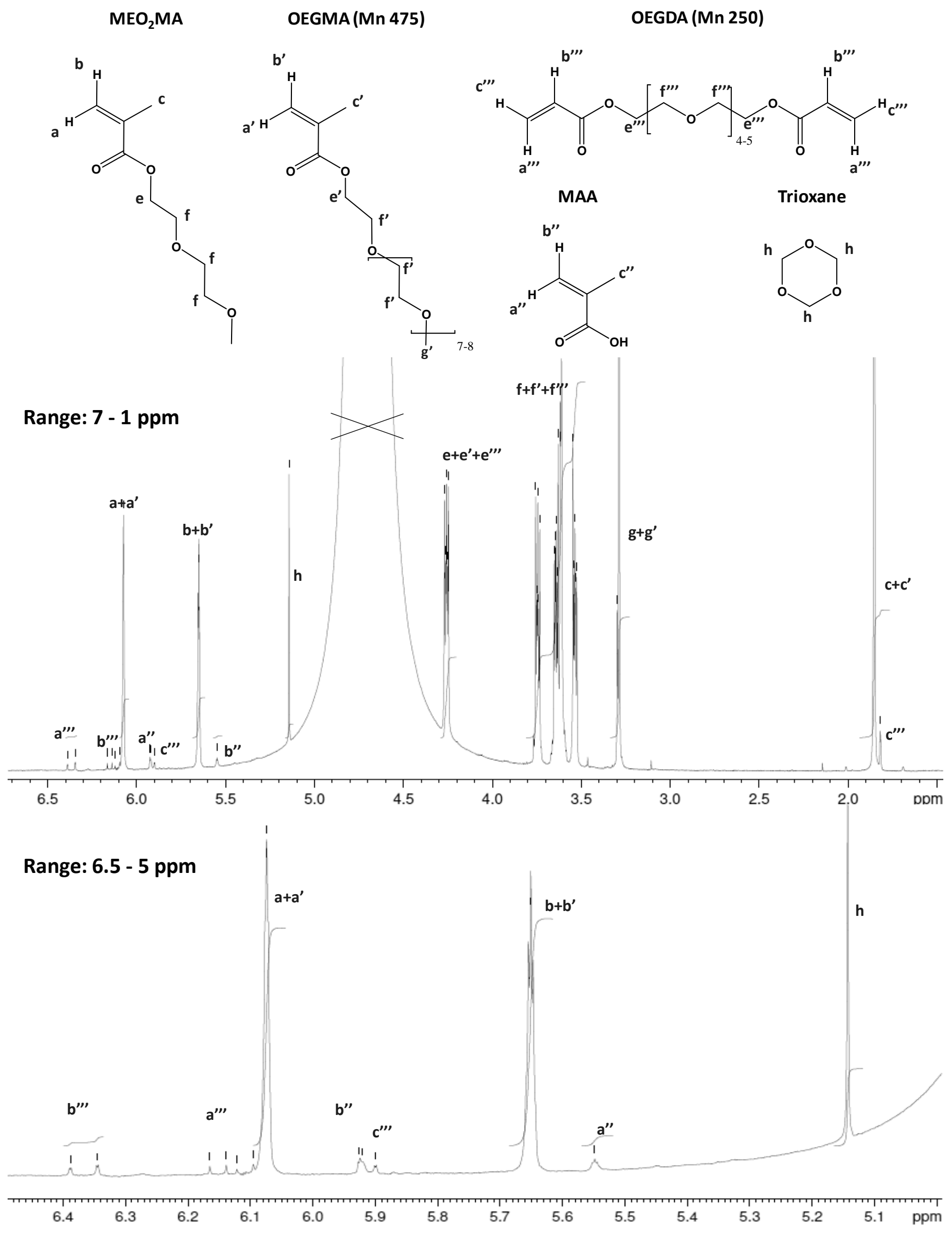

Figure S1: ${ }^{1} \mathrm{H}$ NMR spectra of polymerization medium at initial state 


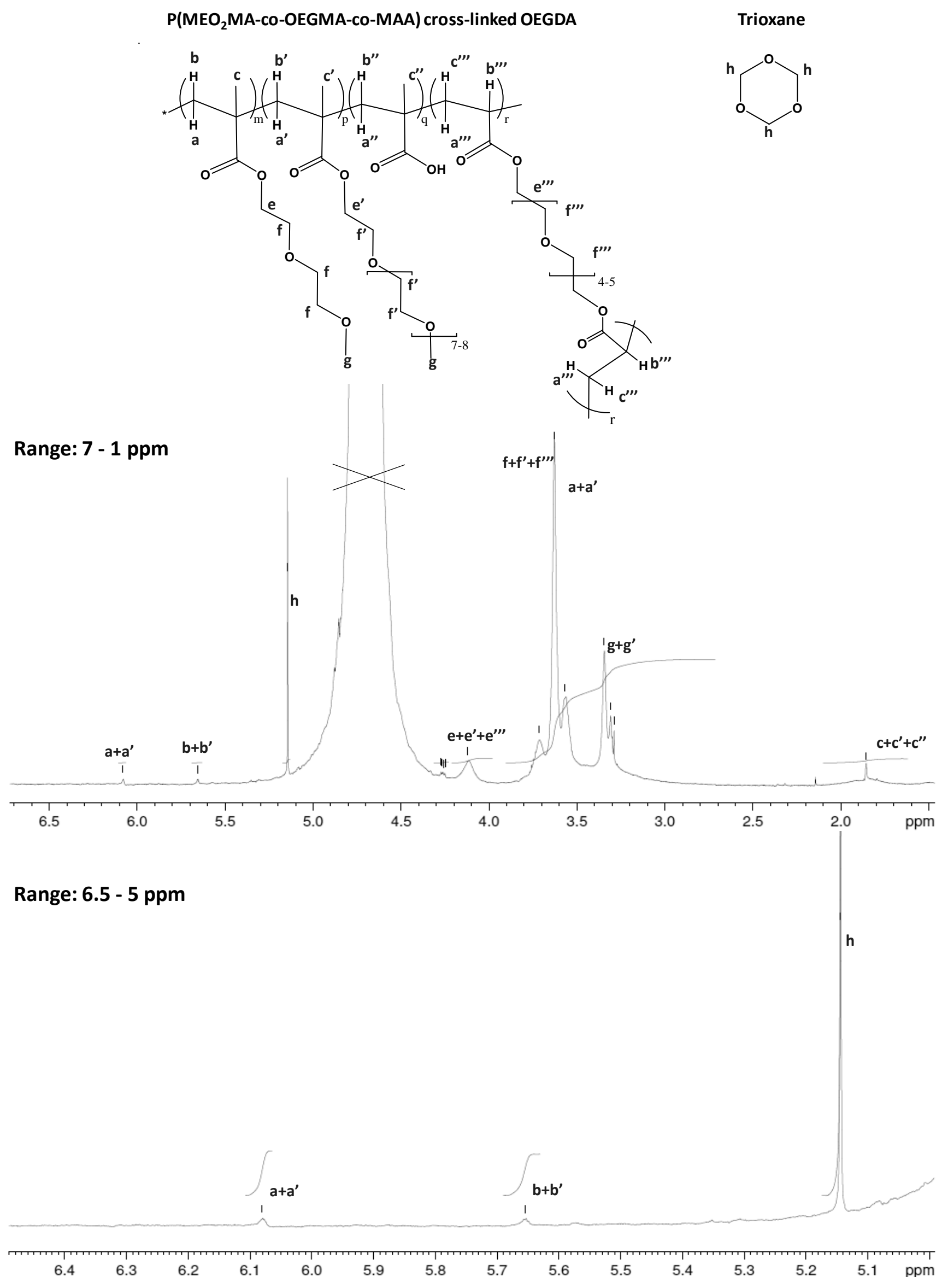

Figure S2: ${ }^{1} \mathrm{H}$ NMR spectra of polymerization medium at final state 


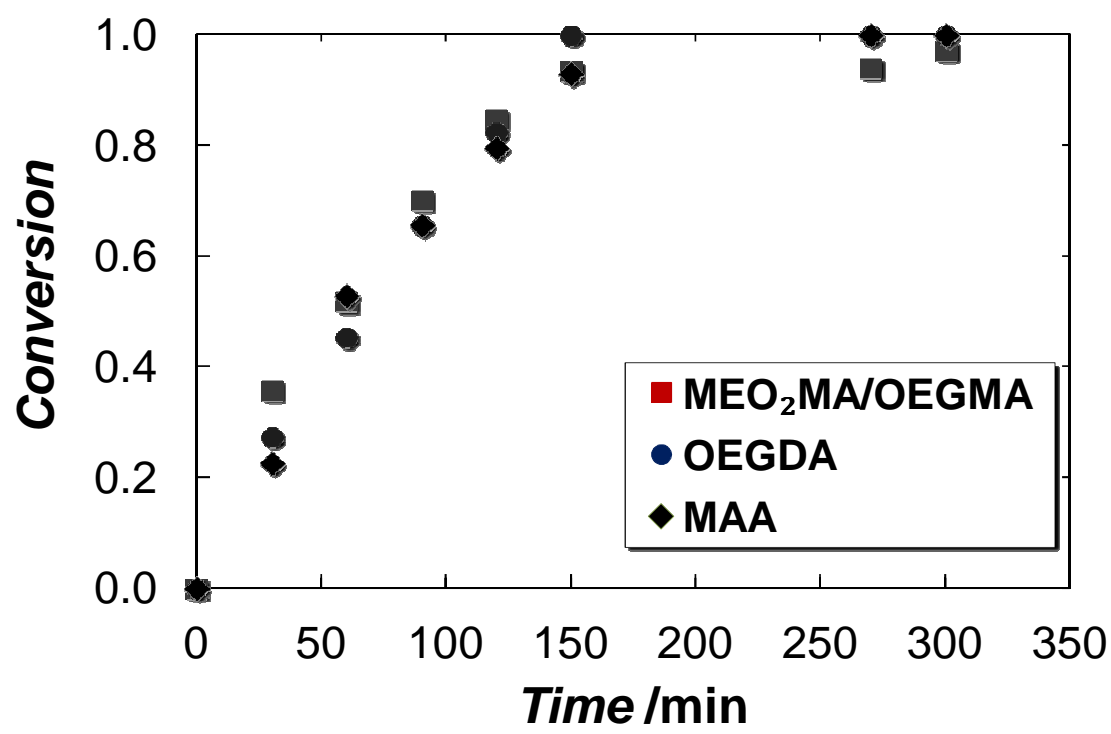

Figure S3: Individual conversions of $\mathrm{MEO}_{2} \mathrm{MA} / \mathrm{OEGMA,} \mathrm{OEGDA}$ and MAA monomers vs time 
Salt-free base-into-acid titration of the P(MEO ${ }_{2} \mathrm{MA}-c o$-OEGMA-co-MAA) microgels by potentiometric and conductometric characterizations

Carboxylic functions titration. Base-into-acid titrations were performed at $20^{\circ} \mathrm{C}$ by coupling conductometric and potentiometric techniques as previously described elsewhere. ${ }^{4}$ Samples were prepared by suspending $50 \mathrm{mg}$ of freeze-dried microgels into $30 \mathrm{~mL}$ of MilliQ water. The $\mathrm{pH}$ of the aqueous dispersion was adjusted below 3.0 with hydrochloride acid $(0.1 \mathrm{M}$ solution of $\mathrm{HCl}$ ) in order to protonate all carboxylic acid groups. A freshly prepared solution of sodium hydroxide $([\mathrm{NaOH}]=1.55 \mathrm{mM})$ was used for titration.

The molar content of $\mathrm{COOH}$ units into the microgels was calculated from the conductivity versus $\mathrm{NaOH}$ volume curves using the standard extrapolation/intersection method to determine the titration endpoints (represented in Figure S4). The concentration of $\mathrm{COOH}$ units into the microgel was calculated using equation Eq. S2. The results are summarized in Table S2:

$$
[\mathrm{COOH}]=\frac{[\mathrm{NaOH}]_{\text {titrant }} \cdot\left(\mathrm{Veq}_{2}-\mathrm{Veq}_{1}\right)}{m_{\text {microgel }}}\left(\mathrm{mmol}_{\mathrm{COOH}} \cdot \mathrm{g}_{\text {microgel }}{ }^{-1}\right)
$$

$\mathrm{V}_{\text {eq1 }}$ and $\mathrm{V}_{\text {eq2 }}$ are respectively the volume of $\mathrm{NaOH}$ added to neutralize the excess of $\mathrm{HCl}$ and the volume of $\mathrm{NaOH}$ added to neutralize $\mathrm{COOH}$ units of the microgel (see Figure S4).

The degree of ionization of carboxylic acid functions $\alpha$ and their acidity constant $\mathrm{p} K_{\mathrm{a}}$ (presented in Figure S5 and Figure S6) were calculated from potentiometric titration data using the following equations:

$$
\begin{gathered}
\alpha=\frac{V_{N a O H, 1 m M}-V_{e q 1}}{V_{e q 2}-V_{e q 1}} \\
p K a=p H-\log \left(\frac{\alpha}{1-\alpha}\right)
\end{gathered}
$$

With, $\mathrm{V}_{\mathrm{NaOH}, 1 \mathrm{mM}}$ is the volume of $\mathrm{NaOH}$ solution at a concentration of $1 \mathrm{mM}$. 


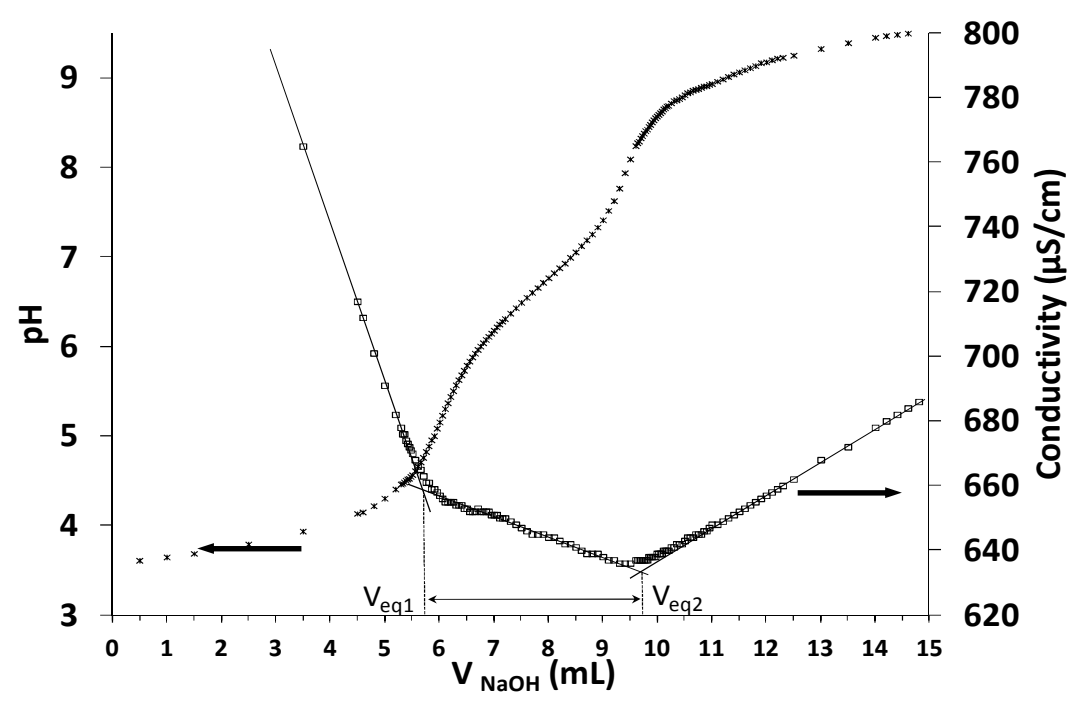

Figure S4: Potentiometric (x) and conductometric $(\square)$ titrations of $\mathrm{P}\left(\mathrm{MEO}_{2} \mathrm{MA}-\mathrm{co}\right.$ OEGMA-co-MAA) microgels

Table S2 : Molar content of carboxylic acid functions per gram of microgel (in mmol.g microgel $^{-1}$ ) determined by titration using conductometry data.

\begin{tabular}{cc}
\hline $\begin{array}{c}{[\mathrm{COOH}]_{\text {theoretical }}} \\
\text { mmol.g }^{-1}\end{array}$ & $\begin{array}{c}{[\mathrm{COOH}]_{\exp }} \\
\text { mmol.g }^{-1}\end{array}$ \\
\hline 0.233 & $0.169 \pm 0.001)$ \\
\hline
\end{tabular}

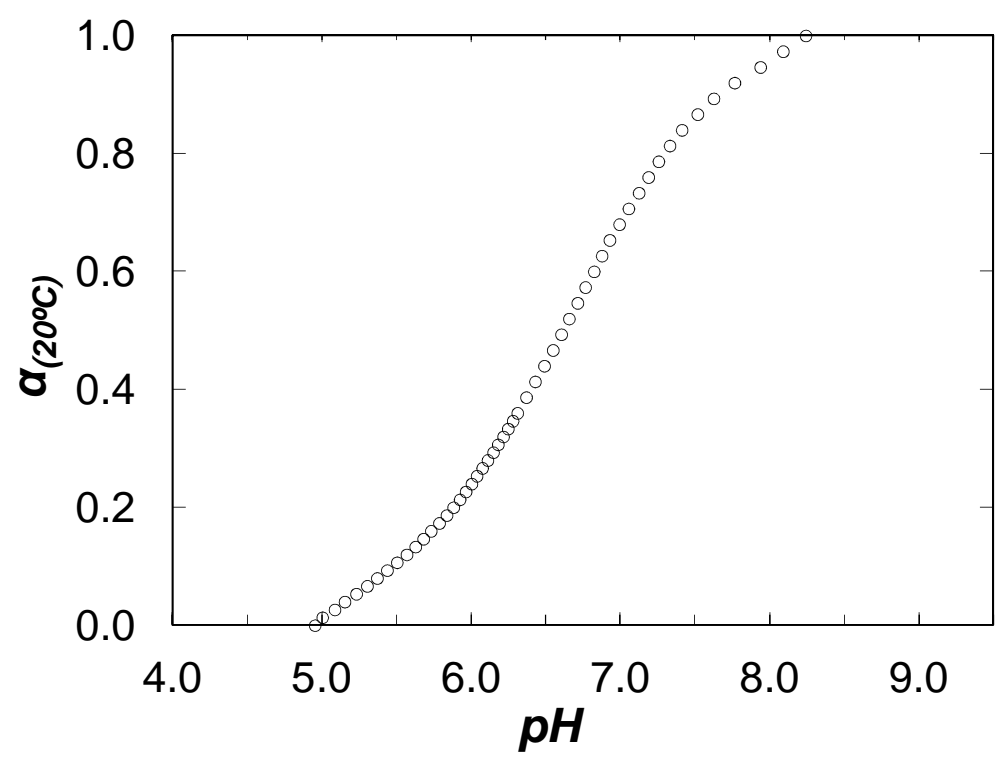

Figure S5: Degree of ionization $\alpha\left(20^{\circ} \mathrm{C}\right)$ of MAA units as a function of $\mathrm{pH}$ at $20^{\circ} \mathrm{C}$. 


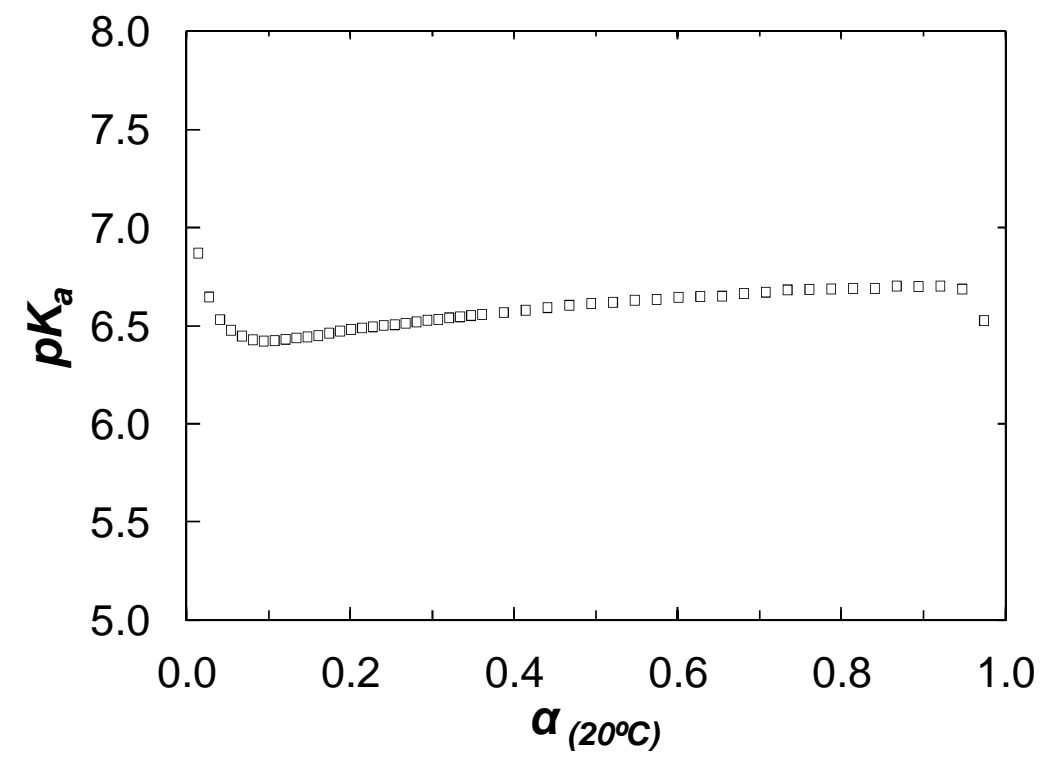

Figure S6: $\mathrm{p} K_{\mathrm{a}}$ of MAA units of $\mathrm{P}\left(\mathrm{MEO}_{2} \mathrm{MA-co-OEGMA-co-MAA}\right)$ microgels as a function of their degree of ionization at $20^{\circ} \mathrm{C}$.

\section{Synthesis of $\gamma-\mathrm{Fe}_{2} \mathrm{O}_{3}$ magnetic nanoparticles}

The cationic $\gamma-\mathrm{Fe}_{2} \mathrm{O}_{3}$ nanoparticles were prepared in water by co-precipitation of metallic salts according to the Massart method. ${ }^{1,2}$ First, $\mathrm{Fe}_{3} \mathrm{O}_{4}$ magnetite particles were prepared by coprecipitation of $\mathrm{FeCl}_{2}$ and $\mathrm{FeCl}_{3}$ at molar ratio $\mathrm{Fe}(\mathrm{II}): \mathrm{Fe}(\mathrm{III})=1: 2$. Iron (II) chloride tetrahydrate (22.6 mmol solubilized in $170 \mathrm{~mL}$ of $1.5 \mathrm{M} \mathrm{HCl}$ solution) was added into an aqueous solution of iron (III) chloride hexahydrate $(45.1 \mathrm{mmol}$ in $500 \mathrm{~mL}$ of water). Then 43 $\mathrm{mL}$ of ammonium hydroxide solution $(28-30 \mathrm{w} / \mathrm{w})$ was added at room temperature under vigorous stirring to produce a black solid suspension composed of flocculated $\mathrm{Fe}_{3} \mathrm{O}_{4}$ magnetite particles. $\mathrm{The} \mathrm{Fe}_{3} \mathrm{O}_{4}$ magnetite particles were then oxidized in 2 steps: the aqueous solution of magnetite nanoparticles (NPs) was first mixed with $28.6 \mathrm{~mL}$ of $2 \mathrm{M} \mathrm{HNO}_{3}$ and stirred for 1 hour at room temperature for surface oxidation. In a second step, $85.7 \mathrm{~mL}$ of $\left[0.33 \mathrm{M} \mathrm{Fe}\left(\mathrm{NO}_{3}\right)_{3}, 9 \mathrm{H}_{2} \mathrm{O}\right]$ solution were added into the flask prior 30 minutes of stirring at reflux condition $\left(\mathrm{T}=100{ }^{\circ} \mathrm{C}\right)$ for inner particle oxidation. The magnetic suspension turned into red color which is characteristic of the formation of maghemite NPs. The NPs were submitted to decantation through a permanent magnet and redispersed with water (3 times). After these 3 cycles, $28.6 \mathrm{~mL}$ of $2 \mathrm{M} \mathrm{HNO}_{3}$ solution were added onto the NPs. The maghemite NPs isolated by a permanent magnet were washed with acetone 3 times prior 
being peptized by adding pure water. A stable aqueous ferrofluid solution composed of $6 \mathrm{wt} \%$ of positively charged maghemite nanoparticles is recovered.

Morphology and hydrodynamic diameter of the maghemite nanoparticles were characterized respectively by transmission electron microscopy (TEM) and dynamic light scattering (DLS). It was observed from TEM images (Figure S7) that maghemite particles are in "rock-like" shape and polydisperse with number average diameter ranging from 5 to $20 \mathrm{~nm}$. Dynamic light scattering indicated an average hydrodynamic diameter of $18 \mathrm{~nm}$ in aqueous dispersion at $\mathrm{pH}$ of 2.

These ferrofluid dispersions are stable in acidic media but start to flocculate at a $\mathrm{pH}$ above 4, with an isoelectric point (or point of zero charge) at $\mathrm{pH}$ 7.2. ${ }^{5}$ The nanoparticle destabilization observed at $\mathrm{pH}$ above 4 is mainly due to the neutralization of the cationic hydroxyl surface groups $\left(\mathrm{OH}_{2}^{+}\right)$.

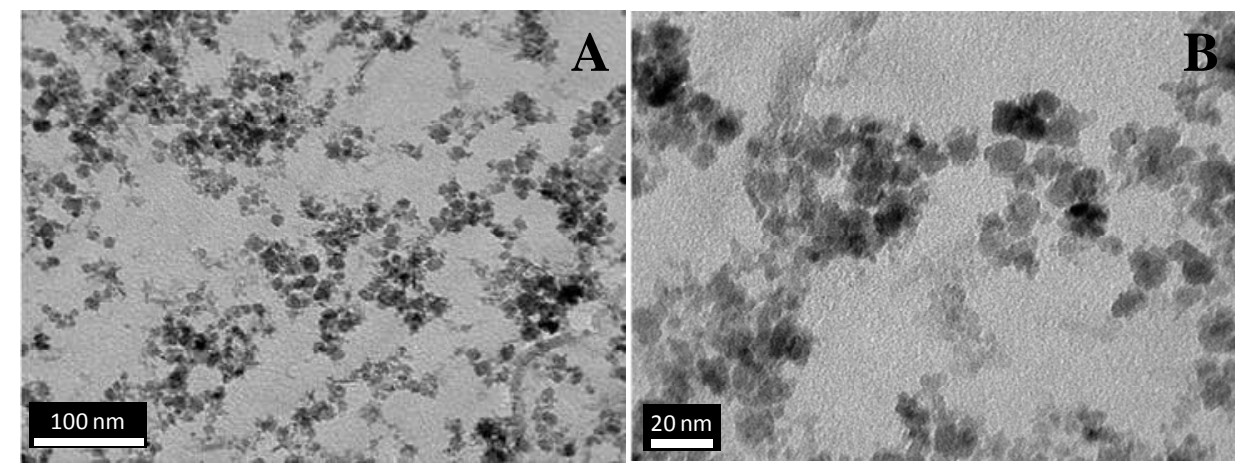

Figure S7 : TEM micrographs of $\gamma-\mathrm{Fe}_{2} \mathrm{O}_{3}$ maghemite nanoparticles at scale of a. $100 \mathrm{~nm}$ and b. $20 \mathrm{~nm}$.

\section{Synthesis of $\gamma$-Fe $\mathrm{Fe}_{2} \mathrm{O}_{3}-\mathrm{P}\left(\mathrm{MEO}_{2} \mathrm{MA}-\mathrm{co}\right.$-OEGMA-co-MAA) hybrid microgels}

The hybrid microgels were prepared by loading the cationic $\gamma-\mathrm{Fe}_{2} \mathrm{O}_{3}$ nanoparticles into the stimuli-responsive $\mathrm{P}\left(\mathrm{MEO}_{2} \mathrm{MA}-\mathrm{co}\right.$-OEGMA-co-MAA) microgels (Table S3). For experiment 1 of Table $\mathbf{S 3}$ as example, $40 \mathrm{~mL}$ of the aqueous dispersion of $\mathrm{P}\left(\mathrm{MEO}_{2} \mathrm{MA}-\right.$-co-OEGMA-coMAA) microgels at a concentration of $1.45 \mathrm{~g} . \mathrm{L}^{-1}$ (pH 6.5) was introduced into a round bottom flask and the $\mathrm{pH}$ was adjusted to 3.0 by addition of nitric acid solution $\left(\mathrm{HNO}_{3} 0.1 \mathrm{M}\right)$. The cationic ferrofluid solution $\left(10 \mathrm{~mL}\right.$ at $\left.1.34 \mathrm{~g} . \mathrm{L}^{-1}\right)$ was added dropwise to the aqueous microgel dispersion under continuous stirring at room temperature and was kept overnight under stirring. The $\mathrm{pH}$ of the aqueous solution of microgels was then adjusted to 7.0 by addition of alkaline solution $(\mathrm{KOH}, 0.5 \mathrm{M})$ in order to destabilize the magnetic nanoparticles into the microgel structure while promoting the stability of the final hybrid microgel by the potassium 
carboxylate functions. Finally the dispersion was purified by 5 centrifugation/redispersion ( 5 $000 \mathrm{rpm}, 20 \mathrm{~min}$ each).

Table $\mathrm{S3}$ : Synthesis of hybrid $\gamma-\mathrm{Fe}_{2} \mathrm{O}_{3}-\mathrm{P}\left(\mathrm{MEO}_{2} \mathrm{MA}-c o-O E G M A-c o-M A A\right)$ microgels.

\begin{tabular}{|c|c|c|c|c|}
\hline \multirow{2}{*}{ Expt } & $\Gamma$ microgel & $\Gamma \gamma-\mathrm{Fe}_{2} \mathrm{O}_{3}$ & $\begin{array}{c}\gamma-\mathrm{Fe}_{2} \mathrm{O}_{3} \\
\text { theoretical }\end{array}$ & $\begin{array}{c}\gamma-\mathrm{Fe}_{2} \mathrm{O}_{3} \\
\text { experimental }\end{array}$ \\
\cline { 2 - 5 } & g. $\boldsymbol{L}^{-1}$ & g. $\boldsymbol{L}^{-1}$ & $w t \%$ & $w t \%$ \\
\hline 1 & 1.49 & 0.299 & 16.6 & 15.9 \\
\hline 2 & 1.5 & 0.599 & 28.5 & 32.6 \\
\hline
\end{tabular}

$\Gamma_{\text {microgel }}$ and $\Gamma_{\gamma \text {-Fe2O3 }}$ are respectively the solid content in microgels and in iron oxide nanoparticles calculated just after addition of both aqueous dispersions. The theoretical value of introduced nanoparticles $\left(\gamma-\mathrm{Fe}_{2} \mathrm{O}_{3}\right.$ theoretical $\left.=\Gamma_{\gamma \text {-Fe2O3 }} /\left(\Gamma_{\gamma \text {-Fe2O3 }}+\Gamma_{\text {microgel }}\right)\right)$ is compared to the experimental fraction of inorganic nanoparticles $\left(=\gamma-\mathrm{Fe}_{2} \mathrm{O}_{3}\right.$ experimental $)$ measured experimentally by thermogravimetric analysis (Figure S8).

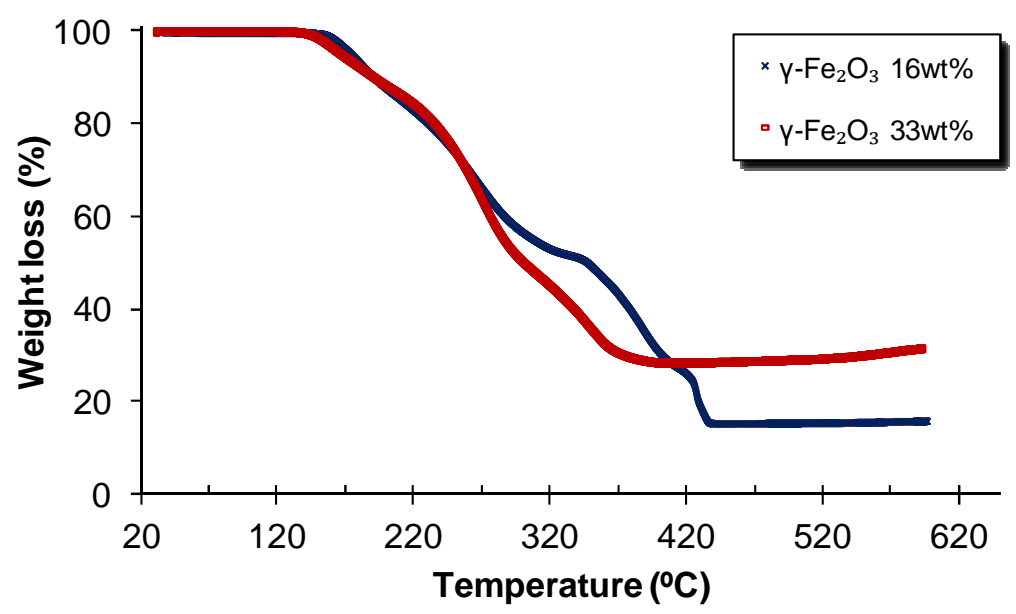

Figure S8 : Thermogravimetric plots of the hybrid $\gamma-\mathrm{Fe}_{2} \mathrm{O}_{3}-\mathrm{P}\left(\mathrm{MEO}_{2} \mathrm{MA}\right.$-co-OEGMAco-MAA)/ microgelsloaded with two different amount of ferrofluid.

Transmission Electron Microscopy (TEM) of P(MEO ${ }_{2} \mathrm{MA-co-OEGMA-co-MAA)}$ microgels and $\gamma$-Fe $\mathrm{Fe}_{2} \mathrm{O}_{3}$-P(MEO $\left.\mathrm{MA}_{2} \mathrm{MA-co-OEGMA-co-MAA}\right)$ hybrid microgels

The aqueous microgel dispersions at a concentration of $0.1 \mathrm{mg} \cdot \mathrm{mL}^{-1}$ were cast onto the TEM copper grids and dried at room temperature for 24 hours before TEM analysis. 


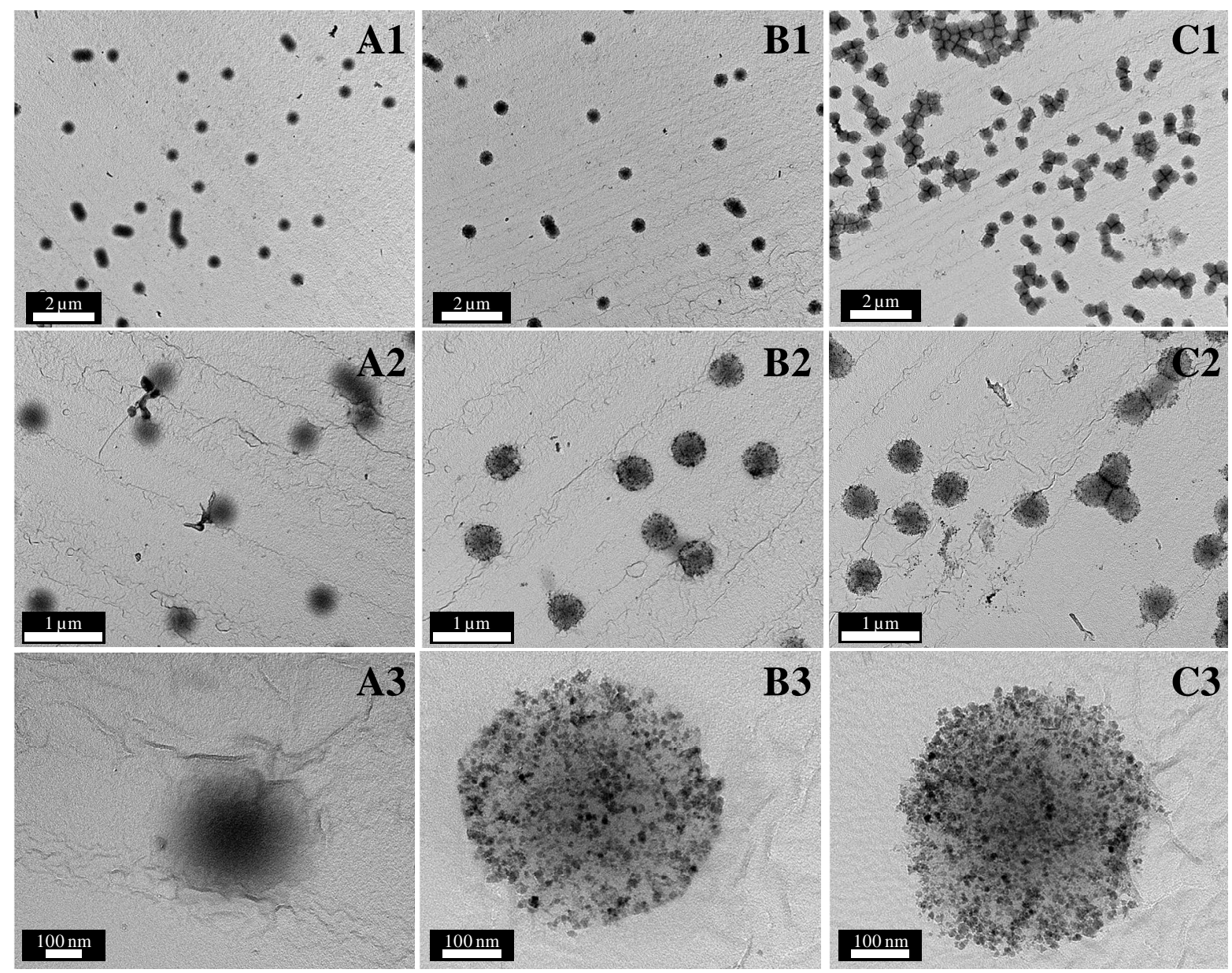

Figure S9: TEM micrographs of A/ P(MEO 2 MA-co-OEGMA-co-MAA) microgels ; $\mathrm{B} / \gamma$ $\mathrm{Fe}_{2} \mathrm{O}_{3}-\mathrm{P}\left(\mathrm{MEO}_{2} \mathrm{MA}-\mathrm{co}-\mathrm{OEGMA}-\mathrm{co}\right.$-MAA) hybrid microgels loaded with $15.9 \mathrm{wt} \%$ of magnetic NPs.and $\mathrm{C} / \gamma$-Fe $\mathrm{F}_{2} \mathrm{O}_{3}-\mathrm{P}\left(\mathrm{MEO}_{2} \mathrm{MA}-\mathrm{co}\right.$-OEGMA-co-MAA) hybrid microgels loaded with $32.6 \mathrm{wt} \%$ of magnetic NPs.

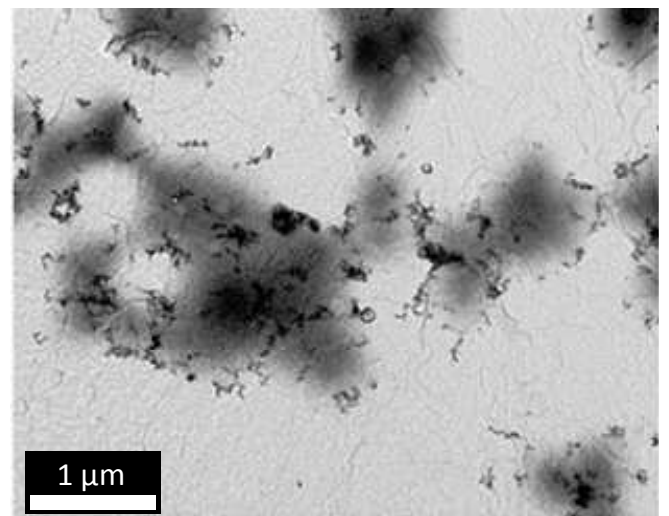

Figure S10: TEM micrographs of acid-free $\mathrm{P}\left(\mathrm{MEO}_{2} \mathrm{MA-co-OEGMA}\right)$ microgels loaded with 4.7 wt\% of magnetic NPs.

\section{Methods}

Nuclear Magnetic Resonance (NMR) spectroscopy. ${ }^{1} \mathrm{H}$ NMR spectra were recorded using a Brüker $400 \mathrm{MHz}$ spectrometer at $25^{\circ} \mathrm{C}$.

Conductometric and potentiometric techniques. A graphite electrode connected to a CDM230 conductivity meter (Radiometer Analytical, France) and SenTix 81 pH-electrode connected to 
WTW pH3310 pH-meter (WTW GmbH, Germany) were used simultaneously in microgel dispersions under continuous stirring.

Transmission Electron Microscopy. Hybrid multiresponsive microgels architecture were observed in dried state by transmission electron microscopy with a Philips CM12 using an accelerating voltage of $120 \mathrm{kV}$ at room temperature.

Thermogravimetric analyses. $\gamma-\mathrm{Fe}_{2} \mathrm{O}_{3}$ nanoparticles loading were determined by thermogravimetric analyses on a TGA Q50, TA Instruments at a heating rate of $10^{\circ} \mathrm{C} \cdot \mathrm{min}^{-1}$ under nitrogen.

Dynamic Light Scattering (DLS). Hydrodynamic diameters of microgels were measured with a Vasco-2 Particle Size Analyzer from Cordouan Technologies (Pessac, France) working at an angle of $135^{\circ}$ and a wavelength of $658 \mathrm{~nm}$. Autocorrelation functions were recorded using a multi-acquisition mode and apparent diffusion coefficients were determined via the PadeLaplace inverse algorithm and the second-order cumulant methods of a large number of measurements. Hydrodynamic radii were determined by the Stokes-Einstein equation (Eq. S5) and particle size distribution (PSD) is given by the cumulant analysis method (a sample is considered monodisperse for values below 0.1). All calculations were performed using the NanoQ software.

Particle size of the hybrid microgels were measured using a Zetasizer Nano S90 from Malvern working at an angle of $90^{\circ}$, using a $4 \mathrm{~mW}$ He-Ne laser at $633 \mathrm{~nm}$. All calculations were performed using the Nano DTS software.

$$
D_{z}=\frac{k_{B} T}{6 \pi \cdot \eta \cdot r}
$$

Where $k_{B}$ is the Boltzmann constant, $T$ is the absolute temperature, $\eta$ is the viscosity of the medium, $\mathrm{r}$ is the hydrodynamic radius, and $\mathrm{D}_{\mathrm{Z}}$ is the apparent diffusion coefficient.

For measurements of the hydrodynamic diameter performed at different temperatures, the change of the water viscosity with temperature was taken into account. Samples were equilibrated for $15 \mathrm{~min}$ at each temperature before analysis.

\section{References}

(1) Massart, R. IEEE Trans. Magn. 1981, 17, 1247.

(2) Bee, A.; Massart, R.; Neveu, S. J. Magn. Magn. Mater. 1995, 149, 6.

(3) Cai, T.; Marquez, M.; Hu, Z. Langmuir 2007, 23, 8663.

(4) Hoare, T.; Pelton, R. Langmuir 2004, 20, 2123. 
(5) Bacri, J. C.; Perzynski, R.; Salin, D.; Cabuil, V.; Massart, R. J. Colloid Interface Sci. 1989, 132, 43. 